\title{
Characteristics of Asphalt Concrete Mixed Using Aggregates Coated by Low Density Polyethylene (LDPE) Plastic Waste
}

\author{
Ni Luh Putu Shinta Eka Setyarini, and Anissa Noor Tajudin
}

\begin{abstract}
Road is one of the important infrastructures in facilitating the mobility of goods and services in order to improve the national economy, but most of the roads are damaged by the effects of weather. The rain water intrusion into the pavement layer make accelerates erosion process. The asphalt erosion processes on the aggregate adhesion causing road damage. It needs a material can coat the aggregate so that of the erosion can be minimized. The Materials can be used to covered aggregate surface is Low Density Polyethylene (LDPE ) plastic waste. The volume of LDPE plastic waste used as much as $5 \%, 7 \%$ and $10 \%$ of the aggregate sieve retained no.8. LDPE plastic waste is made in the form a plastic waste pieces and the test sample made with 4" diameter and 2.7" width in the form of cylinder. Marshall testing was performed on all samples with the result that the addition of LDPE plastic waste can increase the stability until $63.75 \%$ compared to conventional concrete asphalt mixture.
\end{abstract}

Index Terms - asphalt, LDPE plastic waste, Marshall, stability

\section{INTRODUCTION}

$\mathbf{R}_{\text {oft }}^{\text {of }}$ oad is the land transportation infrastructure which is one of the important elements in the effort to facilitate the mobility of goods and services in order to improve the national economy. To achieve this, the provision of land transportation infrastructure can't be separated from the provision of material of the road construction itself. Natural aggregates that are often used for pavement construction material are non-renewable raw materials and in the long run the availability will be exhausted.

Asphalt is a material that at room temperature in the form of solid until somewhat dense, and is thermoplastic [1]. So, the asphalt will melt if heated to a certain temperature and solid again if the temperature drops. Asphalt and aggregates, is pavement-mixing material. The effect weather, which is the rain water intrusion into the layers construction pavement became the acceleration of road damage and aggregate weathering. Therefore the need for a material that can help coating aggregate material other than asphalt in the manufacture of road pavement construction materials.. The alternative material is Low Density Polyethylene (LDPE) plastic waste that can be taken from waste plastic food bags [2],

N.L.P.S.E Setyarini is with the Department of Civil Engineering, Tarumanegara University, 11440, West Jakarta, Indonesia (e-mail: niluhs(a,ft.untar.ac.id) the use $10 \%$ of plastic waste in pavement mixture, can reduce $3 \%$ void from conventional mixture. This study is expected to provide data on the pavement material in terms of the characteristics of the concrete asphalt mixture, when used LDPE plastic waste as an coating. The study is also expected to provide an alternative use of existing LDPE plastic waste by estimating the amount of waste that can be used, thus being the answer to minimize pollution and degradation of environmental due to LDPE plastic waste.

\section{A. Purpose and Objective}

The purpose and objective of this research is to know the effect of the addition of LDPE plastic waste to the increase of asphalt mixture characteristics and to determine the optimum bitumen content of the aggregate mixture and the LDPE plastic waste to obtain better mixture characteristics of asphalt concrete.

\section{B. Problem Formulation}

Good planning is the first step in the successful construction of pavement to obtain service age according to plan. To obtain a longer usage life then roads can be designed with the involvement of certain substitute materials.

The use of LDPE plastic waste as an additive material to the concrete asphalt mixture is expected to improve the stability of the mixture itself and give a good effect on the properties of the mixture.

The problems in this study are the comparison between Marshall characteristic test of between conventional concrete asphalt mixture and concrete asphalt mixture with LDPE plastic waste.

\section{Scope of Problem}

In this study, the problem is limited only to the characteristics of concrete asphalt mixtures using LDPE plastic waste as a aggregate coating. This research is conducted in the laboratory with Marshall test and the collection of data in the form of journals as a reference to be poured in the basic theory.

\section{Research Methods}

The plastic waste used in this study serves as an additional material to aggregate coating, the material is a part of the

A.N. Tajudin is with the Department of Civil Engineering, Tarumanegara University, 11440, West Jakarta, Indonesia (e-mail: nissatajudin@yahoo.com). 
concrete asphalt mixture. Tests conducted in this study according guidelines from DGH 2010 Division 6 revision 3.

\section{A. Stages of Preparation}

Preparation of materials includes activities procurement of materials to be used in research. The materials used in this research include coarse aggregate, fine aggregate, asphalt and LDPE plastic waste.

Aggregates are a broken stone such as, gravel, sand, or other minerals in the form of both natural and artificial products. Aggregates are granular materials, such as sand, gravel, crushed stone used together with a bonding medium to form an asphalt or mortar.

The concrete asphalt layer is a layer of highway construction, which is composed of a mixture of asphalt and aggregate with continuous graded, mixed, spread and compacted in a hot state

\begin{tabular}{lcccr}
\hline Aggregate & Specification & Results & at $\begin{array}{r}\text { a } \\
\text { certain }\end{array}$ \\
\hline Impact & $\leq 30 \%$ & $28.4 \%$ & & \\
Crushing & $\leq 30 \%$ & $8.21 \%$ & & \\
Adhesion to Asphalt & $\geq 95 \%$ & $97 \%$ & & \\
Abrasion & $\max 40 \%$ & $24.9 \%$ & & \\
Thickness and Flakiness & $\operatorname{max.10\% }$ & $1.9 \% ;$ & \\
\hline
\end{tabular}

temperature. The aggregate material comprises a mixture of coarse aggregates, fine aggregates, and fillers.

The mechanical properties of LDPE plastic types are strong, slightly translucent, flexible and somewhat fatty surfaces. At temperatures below 60 degrees Celsius is very resistant to chemical compounds, water vapor protection is quite good, but not good for other gases such as oxygen.

B. Material testing

The materials used in this research consist of coarse aggregate, fine aggregate, asphalt and waste of LDPE plastic which is tested in accordance with the test method used.

\section{Mixed planning}

The asphalt level approaches the optimum used by $6 \%$ of the total weight of aggregate (1100 grams) or as much as 66 grams. Plastic waste content of LDPE is planned at 5\%,7\% and 10\%.

\section{Preparation of Specimens}

At this stage the aggregate is weighed according to the gradation plan of each fraction and filter. Then the aggregate is heated to $165^{\circ} \mathrm{C}$, and then the weighed plastic is mixed into the pan containing the aggregate being heated and stirred until well mixed, after which it is mixed with hot asphalt and then stirred again until evenly distributed. Then the mixture is put into the mold to be pounded as much as $2 \times 75$ times. The test specimen is made of two (3) pieces for each bitumen content.

\section{E. Testing of Specimens}

Testing the specimen uses a Marshall Test tool. A Marshall tool is a press device equipped with a proving ring used to measure the stability and flow meter values used to measure flow.

\section{ANALYSIS AND DISCUSSION}

The first step in this research, we examined the material that will be used to examine the physical characteristics of materials: aggregate, asphalt, and waste of LDPE plastic. It is necessary to know whether the type of aggregate, asphalt, and waste of LDPE plastics used qualified to meet specifications or not. This study was conducted in accordance with existing testing guidelines and also supported with calibrated equipment.

\section{A. Aggregate}

From the examination of the characteristics of coarse aggregate, fine aggregate, and filler used for asphalt concrete mixture (LASTON), the results are as in Table IA and Table IB.

TABLE IA

RESULTS OF THE AGGREGATE CHARACTERISTIC EXAMINATION

\begin{tabular}{lll}
\hline Aggregate & Specification & Results \\
\hline BJ. Aggregate Coarse & Min. 2.5 & 2.56 \\
BJ. Fine Aggregates & Min. 2.5 & 2.5 \\
BJ. Filler & Min. 2.5 & 2.5 \\
\hline
\end{tabular}

TABLE IB

RESULTS OF THE AGGREGATE CHARACTERISTIC EXAMINATION

\section{B. Asphalt}

The result of examination of asphalt characteristic with Esso Pen 60/70 asphalt material done in Road Laboratory of Civil Engineering Department Faculty of Engineering Tarumanagara University is presented in Table II.

TABLE II

\begin{tabular}{lll}
\multicolumn{3}{l}{ RESULTS OF ASPHALT CHARACTERISTIC INSPECTION } \\
\hline Asphalt & Specification & Results \\
\hline Penetration & $60 / 70$ & $69 / 70$ \\
Ductility & $\geq 100 \mathrm{~cm}$ & $112 \mathrm{~cm}$ \\
BJ. Asphalt & $\geq 1$ & 1.016213 \\
Softening Point & $\geq 48^{\circ} \mathrm{C}$ & $53^{\circ} \mathrm{C}$ \\
Flash and Burning & $\geq 232^{\circ} \mathrm{C}$ & $325^{\circ} \mathrm{C} ;$ \\
Point & & $340^{\circ} \mathrm{C}$ \\
\hline
\end{tabular}

\section{LDPE Plastics}

Waste plastic used is a plastic type LDPE (Low Density Polyethylene) obtained from the collectors located in Dadap. From the results of the specific gravity test, we obtain the weight of LDPE plastic waste amounted to $0.919 \mathrm{gr} / \mathrm{cm}^{3}$, the result as in Table III.

TABLE III

RESULTS OF EXAMINATION OF LDPE PLASTIC

\begin{tabular}{lll}
\hline Plastic & Specification & Results \\
\hline $\begin{array}{l}\text { Specific } \\
\text { gravity }\end{array}$ & $\geq 0.91 \mathrm{gr} / \mathrm{cm}^{3}$ & 0.919 \\
\hline
\end{tabular}

\section{Standard Immersion Marshall Test Results (30 minutes)}


It can be seen in Fig 1 that the density value of the concrete asphalt mixture without the addition of LDPE plastic waste is higher than the mixture using LDPE plastic waste additive. This is due to the LDPE plastic waste involved covered with asphalt make reduces the level of asphalt that should fill the voids in the mix.

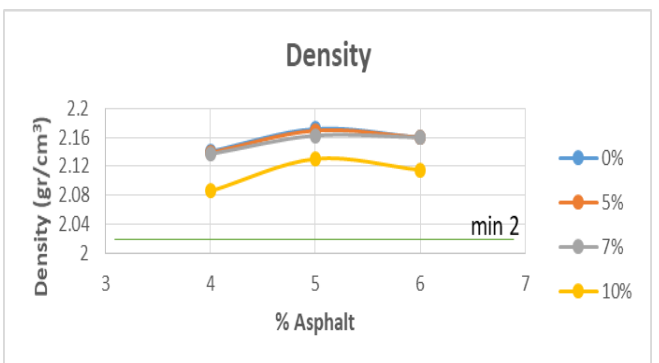

Fig 1. Comparison Chart between Asphalt Levels with Density

Can be seen in Fig. 2, the addition of bitumen content, VFWA value also increased. Judging from the addition of LDPE plastic waste content, VFWA value is increasing, this is caused when the mixing of LDPE plastic waste which is also covered with asphalt reduces the amount of asphalt that should fill the void in the mixture.

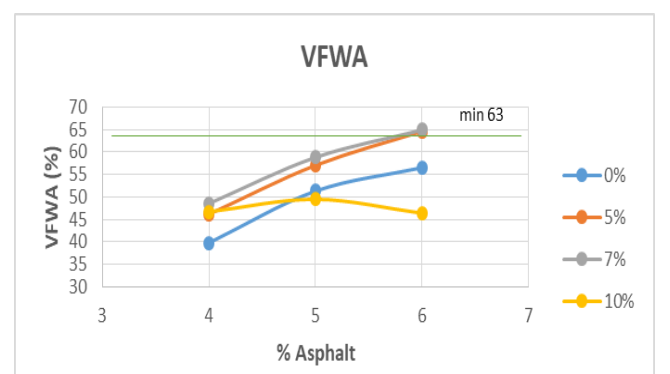

Fig 2. Comparison Chart between Asphalt Levels with VFWA

From Fig 3 comparison graph between asphalt content with VITM, we can see that the higher bitumen content, the smaller the VITM value. And in mixtures with $5 \%, 7 \%, 10 \%$, LDPE plastic content the VITM value decreases, this is due to the added LDPE plastic waste content inhibiting the asphalt void in the mixture.

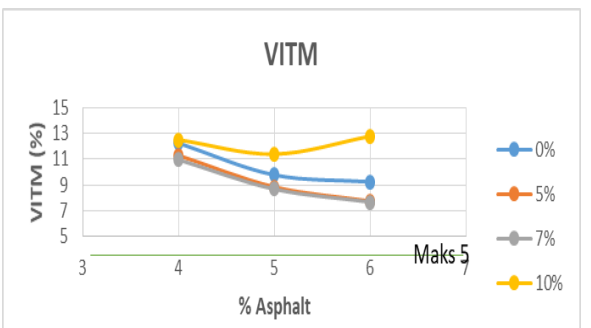

Fig. 3. Comparison Chart between Asphalt Levels with VIM.

In Fig 4, it appears that the addition of asphalt content in the three variations will first decrease the value of VMA then if the bitumen content is added then the VMA value will increase. This happens because when the asphalt is added became that the distance between aggregates decreases, but if the asphalt content increase, will also cause the aggregate spacing to become larger.

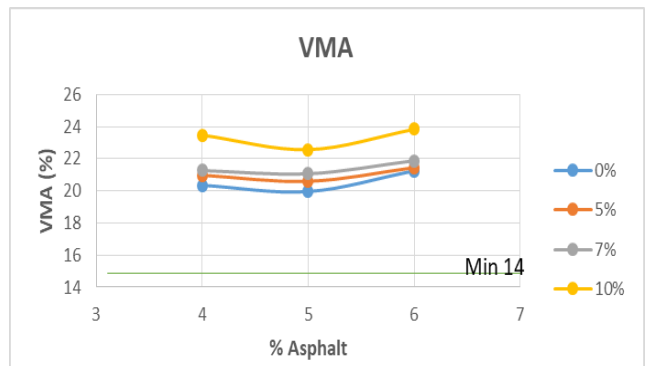

Fig 4. Comparison Chart between Asphalt Levels with VMA.

It can be seen from fig 5, the graph of the test result with the addition of the LDPE plastic waste content, the stability value tends to increase. This is due to the added LDPE plastic waste in the form of angled fibers and the asphalt-covered aggregates locking each other up nicely. The aggregate position does not easily move from its place when it is loaded, so its stability increases.

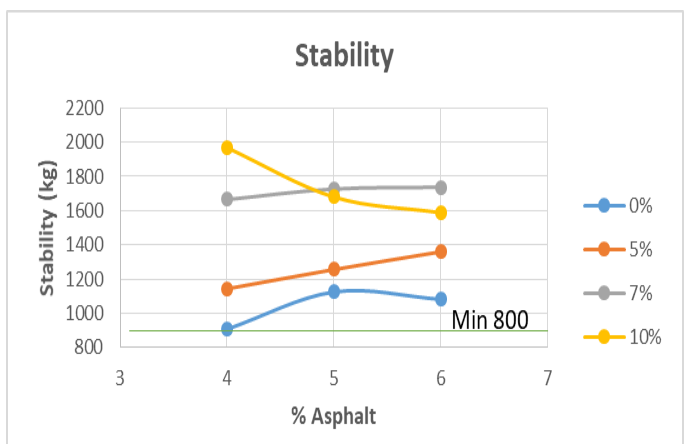

Fig 5. Graph of Comparison between Asphalt and Stability.

From Fig 6 graph the comparison of asphalt content with flow. It can be seen that flow value tends to increase at the time of adding more asphalt content and at the time of addition of LDPE plastic waste. With the addition of LDPE plastic waste content, the flow value will be higher than if the mixture is not added by LDPE plastic waste, this is because the nature of the plastic itself is softer than the rock. But in $10 \%$ LDPE plastic waste content, the value tend decrease But in $10 \%$ LDPE plastic waste content, the flow value tend decrease that because of the asphalt mixture more supple.

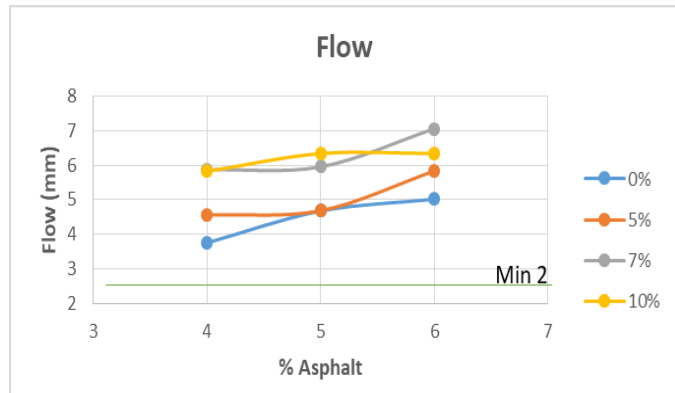

Fig 6. Comparison Chart between Asphalt Levels with Flow 
E. Comparison of Standard Immersion Results with Immersion $0.5,24,48$, and 72 Hours

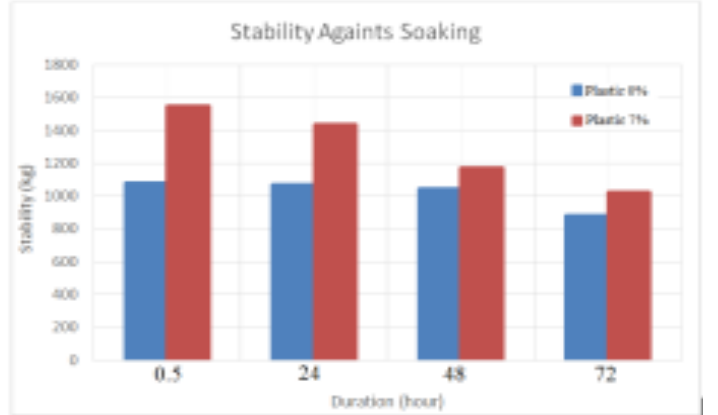

Fig 7. Graphic of Stability against Soaking $0.5,24,48$ and 72 Hours.

Seen on the Fig 7 graphic of stability against soaking with duration 30 minutes , 24, 48, and 72 hours. The longer the immersion time, the stability value will decrease at the level of plastic $0 \%$ and as well as on the content of 7\% LDPE plastic waste. This decrease in stability value occurs because asphalt is thermoplastic material hence the nature of the asphalt is greatly influenced by temperature.

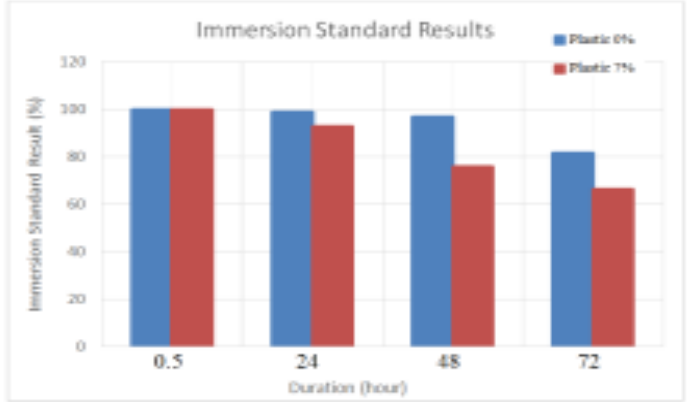

Fig 8. Graph of Immersion Standard Result against Soaking 0.5, 24, 48 and 72 Hours

In fig 8 the flow of the graphic of 30 minutes, 24,48 and 72 hours immersion shows that. The flow value will tend to increase at the time of addition of 7\% LDPE plastic waste content. This indicates that the use of LDPE plastic waste will improve the plastic condition of the mixture so that pavement will be more vulnerable to loading.

\section{F. Discussion on the Use of LDPE Plastic Waste in Mixture}

Technical Consideration, base on research LDPE plastic waste can be used as an additional material for gradation aggregate pass sieve no. 4 and stifled filter no. 8 because the volumetric and Marshall values still meet the required specifications on all variations in the plastic content under test.

Environmental Consideration with the use of LDPE plastic waste in large volumes for a pavement construction, a significant LDPE plastic waste treatment solution is obtained. In $\mathrm{AC}-\mathrm{BC}$ mixture with 7\% plastic content variation, the weight of LDPE plastic waste is $7 \%$ of total weight of gradation no8. Thus every $1 \mathrm{~m} 3$ of AC-BC mixture having a specific gravity of $2.34 \mathrm{gr} / \mathrm{cm} 3$ or $2,340 \mathrm{~kg}$ will use LDPE plastic waste as much as $7 \% \times 2340 \mathrm{~kg}=164 \mathrm{~kg}$. So for AC-BC mixture with $75 \mathrm{~cm}$ pavement thickness and road width [2 $(2 \times 3.5)] \mathrm{m}$ with 1 $\mathrm{km}$ road length can utilize LDPE plastic waste of 1,71 tons

\section{CONCLUSION}

Based on the research that has been done by using Low Density Polyethylene (LDPE) plastic waste as a substitute for the coarse aggregate of Asphalt Concrete - Binder Course (ACBC) mixture, the following conclusions are obtained:

- LDPE plastic waste can be used as an additional material for gradation aggregate pass sieve no. 4 and stifled filter no. 8 because the volumetric and Marshall values still meet the required specifications on all variations in the plastic content under test.

- The stability value tends to increase when the concrete asphalt mixture is covered by the LDPE plastic waste with the result of the stability value increased as much as $63.75 \%$ in the manufacture of the specimen with the asphalt content approaching the optimum in normal 30minutes immersion.

- AC-BC mixture with LDPE plastic waste as a feasible coating to be applied on terms of several aspects, namely engineering, economics, and environment. Technically the use of plastic waste meets the specification requirements, economically reducing government costs in the case of plastic waste disposal, and environmentally can be a handling solution for undegradable plastic waste.

- Flow value increases when plastic content increases. Flow value increased as much as $65.35 \%$ on the manufacture of specimens with asphalt content approaching optimum in 30 minutes immersion.

- The air void in the concrete asphalt mixture decreased by $1.08 \%$ at the time of adding the plastic content to the concrete asphalt mixture.

- By adding LDPE plastic waste as much as $7 \%$ of the total weight of gradation no8 in AC-BC mix with LDPE plastic waste. Can reduce LDPE plastic waste of 1,71 tons along $1 \mathrm{~km}$ road.

\section{RECOMMENDATION}

1. Further research is needed to determine the other properties of the AC-BC mixture using plastic waste as an additive to the mixture.

2. Some measuring tools used in the test still require visual observation manually, so there is the possibility of reading errors. For that, required precision and accuracy during the implementation of research so that the data generated accurately.

3. Need to do further research by using other types of plastics and other waste as an alternative. This will maximize the plastic waste treatment solution.

There is a need for further research on the same or different mixture types using different plastic sizes with higher plastic content from this study, considering the highest plastic content used in this study still meets the specification requirements.

\section{REFERENCES}

[1] S. Sukirman, "Highway Flexible Pavement". Bandung : Publisher NOVA, 2003.

[2] Vasudevan, "Utilization of Waste Plastics in Rural Roads", India:College of Engineering,Madurai-15, 2013. 